\title{
The Role of the Immune System on the Cardiac Complications Observed in SARS-CoV-2
}

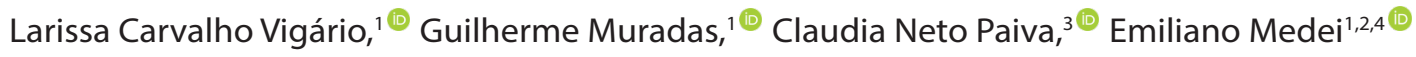 \\ Institute of Biophysics Carlos Chagas Filho, Federal University of Rio de Janeiro,' Rio de Janeiro, RJ - Brazil \\ D'Or Institute for Research and Education (IDOR), ${ }^{2}$ Rio de Janeiro, RJ - Brazil \\ Instituto de Microbiologia Paulo de Góes, Universidade Federal do Rio de Janeiro, ${ }^{3}$ Rio de Janeiro, RJ - Brazil \\ National Center for Structural Biology and Bioimaging, Federal University of Rio de Janeiro, ${ }^{4}$ Rio de Janeiro, RJ - Brazil
}

\section{Abstract}

An acute respiratory syndrome caused by SARSCoV2 was declared a pandemic by the World Health Organization. Current data in the world and in Brazil show that approximately $40 \%$ of patients who died have some type of cardiac comorbidity. There are also robust reports showing an increase in IL-6 / IL-1B / TNF-alpha and the presence of lymphopenia in patients with COVID-19. Our team and others have shown that increased cytokines are the link between arrhythmias/ Left ventricular dysfunction and the immune system in different diseases. In addition, it has been well demonstrated that lymphopenia can not only be a good marker, but also a factor that causes heart failure. Thus, the present review focused on the role of the immune system upon the cardiac alterations observed in the SARS-CoV2 infection. Additionally, it was well described that SARS-CoV-2 is able to infect cardiac cells. Therefore, here it will be reviewed in deep.

\section{Introduction}

The Severe Acute Respiratory Syndrome Coronavirus 2 (SARS-CoV-2) is the RNA virus responsible for the Coronavirus Disease 19 (COVID-19). The epidemics emerged from the city of Wuhan, in China, in December 2019, and rapidly spread worldwide, being declared a pandemic on March 11 by the World Health Organization. ${ }^{1}$

\section{Keywords}

SARS-CoV2; Heart/ immunology; Severe Acute Respiratory Syndrome; Coronavirus/ complications; Heart Diseases/ complications.
Most deaths in COVID-19 are credited to acute respiratory distress syndrome (ARDS). In general, ARDS may be triggered by a variety of inflammatory conditions, such as severe lung damage, severe pneumonia, and sepsis, and is caused by damage to alveolar capillaries endothelia. Such damage causes an increase in lung vascular permeability, allowing fluid to flow inside alveoli and creating a thick hydrophilic film, which makes it difficult for oxygen to access the blood. Moreover, although most severe symptoms of COVID-19 are caused lung damage, some patients may develop severe cardiovascular damage throughout the course of the disease. ${ }^{2}$ Cardiovascular compromise due to COVID-19 was associated with arrhythmias $(16 \%)$, myocardial ischemia (10\%), myocarditis (7.2\%) and shock (1-2\%). ${ }^{3}$

Among infected persons, hypertension, and cardiovascular diseases (CVD) are the most common comorbidities related to severe cases. ${ }^{4}$ An estimated 50\% of hospitalizations of COVID-19 patients are composed of cardiomyopathy patients ${ }^{3}$ and $60 \%$ of deaths occurs among patients with cardiovascular comorbidities. ${ }^{5}$ The high prevalence of cardiovascular disease among COVID-19 co-morbidities demonstrate the importance of a special look on the relations between the coronavirus disease and its possible consequences on the heart. Even though that several cases of cardiac impairment were reported, scarce data is actually available on the presence of SARS-CoV-2 in cardiac tissue. A recent study reported that 78 of 100 patients recently recovered from COVID-19 (78\%) had abnormal cardiovascular magnetic resonance (CMR) findings. ${ }^{6}$

\section{Hypoxia, ischemia, and COVID-19}

Troponins are proteins that composes the contractility units of the muscle cells and have a regulatory role on

Mailing Address: Emiliano Medei

Av. Carlos Chagas Filho, 373. Postal Code: 21941-901, Rio de Janeiro, RJ - Brazil.

E-mail: emedei70@biof.ufrj.br 
the contraction-relaxation cycle and high sensitivity cardiac troponin (hs-cTn) is exclusively expressed in cardiomyocytes. Extremely sensitive to reduced oxygen offer, hs-cTn can be used to detect heart tissue injuries caused by hypoxia, such as to detect heart infarction types I and II, coronary syndromes and possible heart injuries on several respiratory syndromes. ${ }^{7,8}$ Elevated blood levels of hs-cTn were consistently observed in severe COVID-19 and associated with morbidity. ${ }^{7}$ ARDS leads to systemic hypoxia, ${ }^{8}$ the most likely reason for high hs-cTn blood levels. The more severe is the hypoxia, the higher are expected to be the levels of cardiac troponin. ${ }^{7}$ This pattern appears to be common to ARDS from several etiologies. ${ }^{8}$ In fact, troponin is useful as a biomarker to help identify the course of the disease ${ }^{9}$ and high levels of hs-cTn are usually associated with high mortality rates. ${ }^{10}$

The several coagulopathies events triggered by COVID-19 such as anti-phospholipid antibodies, ${ }^{11}$ lung capillary damage ${ }^{12,13}$ and high pro-inflammatory cytokine levels ${ }^{14}$ seem to be implicated in the ischemic myocardial damage associated with the disease. In fact, episodes of heart infarction are frequent in patients with COVID-19, as well as ischemic strokes ${ }^{15}$ and episodes of microvascular and pulmonary thromboembolism. ${ }^{16-19}$ The ischemic heart damage and the cardiac stress produced by altered hemodynamics are causes of heart tissue damage.

\section{Heart Arrhythmias in COVID-19}

A number of cases of heart arrhythmias have been described in the course of severe COVID-19, but understanding the role played by cytokine storm and putative viral myocarditis or even direct tissue infection is complicated by the administration of several drugs that might alter cardiac rhythm, and also by the effects of refractory hypoxemia on heart conduction system.

In the urge to achieve an efficient treatment to SARS-CoV-2 infection, several drugs have been tested worldwide. After an in vitro study ${ }^{20}$ that prove the efficiency of Hydroxychloroquine against the virus, a French research group aimed to evaluate its results in humans. In an open-label non-randomized clinical trial, they concluded a drug effect in clearing viral nasopharyngeal carriage of SARS-CoV-2 in only three to six days. ${ }^{21}$ This way, the authors suggested that, especially in association with Azithromycin, Hydroxychloroquine could be a possible international strategy to the fight against Covid-19. Although a study estimated that $9-11 \%$ of the patients receiving Hydroxychloroquine plus Azithromycin treatment might develop severe QTc prolongation, $>500 \mathrm{~ms}^{22}$ this study did not have an appropriate control to QTC prolongation among COVID-19 patients of similar gravity and did not result in Torsades de Pointes. ${ }^{23} \mathrm{On}$ the other hand, premature ventricular complex followed by polymorphic ventricular tachycardia (Torsades de Pointes), with marked QTc prolongation and wave T inversion, was described in a 64-female patient that had a medical record of nonischemic cardiomyopathy with paroxysmal AF, in the setting of refractory hypoxemia. The patient was being treated with Azithromycin, that was discontinued, and the patient had no further episodes of ventricular arrhythmias. ${ }^{24}$ The separation between rhythm abnormalities caused by drugs and by COVID-19 itself is a difficult, important task.

Heart arrythymias may also develop throughout the course of COVID-19 without any drug association. Bhatla et al., ${ }^{25}$ purpose to evaluate the risk of cardiac arrest and arrythymias in hospitalized patients. They investigated a cohort of 700 patients and detected 53 arrhythmic events, including cardiac arrest, with one case of Torsades de Pointes, Atrial Fibrillation, Bradyarrhythmia and NSVT, but no heart blocks, sustained VT or VF. ${ }^{25}$

To understand the mechanisms involved in such cardiac events, we might reason with previous epidemic knowledge, especially SARS-CoV infection. Yu et al., ${ }^{26}$ analyzed a cohort of 121 patients with SARS-CoV in 2005 and described tachycardia as the commonest cardiovascular manifestation once it occurred in two thirds cases among the infected. Neither fever nor hypotension could explain such alteration in cardiac rhythm, as tachycardia was sustained even in the third week if infection, when febrile manifestation was not present, and in a comparatively small number of patients presenting low blood pressure levels. Nevertheless, sinus bradycardia was a less common condition, but also affected $15 \%$ of patients, although it was somewhat transient compared with sinus tachycardia. Moreover, five possible causes for cardiac arrest were pointed by Pau et al: (1) the lung injury caused by the SARS-CoV virus leads to hypoxemia and thus an unsteady state of the myocardial electricity; (2) SARS-CoV virus directly causes injury to the myocardial cells and/or the conduct system; (3) SARS-CoV infection aggravates the original myocardial pathological change, 
worsening the conduct block; (4) extreme anxiety leads to extra secretion of catecholamine, which causes instability of myocardial electricity. ${ }^{27}$

\section{Cytokine Storm and Heart Function}

Once the virus enters the organism, it uses the ACE2 receptor to invade cells, and then, replicate itself. Type II pneumocytes, epithelial cells of kidneys and ileum, and, also, cardiomyocytes have high ACE2 expression, ${ }^{28}$ but which tissues are in fact usually infected is still a matter of debate. The infection can even directly affect the immune system, once macrophages, monocytes and dendritic cells also express ACE2 on their surfaces, characterizing SARSCoV-2's other targets. ${ }^{28}$ After invading those immune cells, the virus may induce changes in the cytokine and chemokine expressions pattern, increasing their release, in the so-called cytokine storm. ${ }^{29}$ Several cytokines could be released as interferons and also, tumor necrosis factor alpha (TNF- $\alpha$ ), and interleukin-1 (IL-1), IL-6, and IL-18 are also released. ${ }^{28}$

After lower airway infection by SARS-CoV-2, some authors have noticed elevated levels of interleukin-6 (IL-6) in patients' bloodstream, as described by Le et al. ${ }^{30}$ Development of ARDS in COVID-19 is associated to high IL-6 levels ${ }^{31}$ and does not seem to be closely associated to the viral load, but rather to the host's inflammatory response. ${ }^{32}$ Tocilizumab, an anti-IL-6 antibody, acts to reduce the levels of inflammatory markers such as CRP, and although an observational single-arm study did not show much benefit, ${ }^{33}$ there is an ongoing randomized trial in which preliminary results show tocilizumab prevents mechanical ventilation or death, ${ }^{34}$ indicating a pivotal role for IL-6 in the physiopathology of ARDS. Moreover, Tocilizumab reverses the lymphopenia, the decrease in HLA-DR ${ }^{+}$cells and the inhibition of cytotoxic cells induced by the virus, ${ }^{35,36}$ demonstrating that there is an immune dysregulation mediated by an exaggerated inflammatory response in which IL-6 predominates.

Several works have pointed out the important role played by IL-6 $6^{31-36}$ and other several cytokines on cardiac rhythmic and mechanical function. Interleukin-6 was measured in 2329 patients [89.4\% with a left ventricular ejection fraction (LVEF) $\leq 40 \%$ ] of the BIOSTAT-CHF cohort. The authors described an elevated IL-6 levels in more than $50 \%$ of patients. Elevated IL-6 levels were associated with iron deficiency, reduced LVEF, atrial fibrillation and poorer clinical outcomes. In this line, Aromolaran et al., ${ }^{37}$ showed that IL-6 inhibits potassium repolarizing current "IKr", resulting in action potential prolongation through IL-6R and JAK pathway. This finding might help better understanding the basis for the observed clinical QT interval prolongation and is corroborated by a decrease in QTc after anti-IL-6 administration to rheumatoid arthritis patients. ${ }^{38}$ An increment in IL-6 levels ( 10 to 100 times more than reference values) and high circulating levels of TNF $\alpha$ and IL-1 were associated with longer QTc interval and TdP events in chronic inflammatory arthritis patients. ${ }^{39}$ All these evidences point to a possible effect of IL-6 mediating arrhythmias in COVID-19.

Myocardial IL-6 mediates cardiac inflammation and contractile dysfunction after burn plus sepsis. Other works reported that subcutaneous administration of IL-6 to rats leads to a dose-dependent myocardial contractile function deterioration. ${ }^{40}$ In vitro, IL- 6 has a direct negative inotropic effect on isolated papillary muscle, probably related to up-regulation of myocardial nitric oxide synthase $2 .{ }^{41}$ In addition, IL-6 down-regulates the sarcoplasmic reticulum Ca2p - ATPase (SERCA2) in isolated cardiac myocytes. ${ }^{42}$ Finally, administration of IL-6 to rat cardiac myocyte cultures results in reduced expression of a myosin heavy chain, b-myosin heavy chain, and cardiac actin. Collectively, these data support the notion that both IL-6 have a specific direct role in the cardiac function and could directly be involving on the physiopathology different cause of heart failure.

"Cytokine storm" is the phenomenon caused by several different inflammatory cytokines secreted in response to acute SARS-CoV-2 infection, and the levels of IL-1 $\beta$ are under scrutiny as a putative participant. ${ }^{43,44}$ The effects of IL-1 $\beta$ on cardiac electrical function have been explored by many works. ${ }^{45,46}$ We previously demonstrated that IL-1 $\beta$ was able to prolong the ventricular action potential decreasing a transient outward potassium repolarizing current (Ito) in a type-1 diabetes mouse model. ${ }^{47}$ In renal ischemia/reperfusion, it was observed that the treatment with Anakinra (Kineret $\AA$ ) was able to rescue the cardiac function. ${ }^{48}$ In COVID-19, a recent study demonstrated the potential therapeutic action of Anakinra in patients who were admitted to hospital for severe forms of COVID-19 with symptoms indicative of worsening respiratory function. ${ }^{49}$ The results shown that the high dose Anakinra was able to reduce both need for invasive mechanical ventilation in the ICU (cumulative mechanical ventilation-free $72 \%$ Anakinra x 50\% non-treated controls) and mortality (21 days cumulative survival 90\% Anakinra x 56\% non-treated 
controls) among patients with severe forms of COVID-19, without serious side-effects. ${ }^{50}$ Although no reports exist yet concerning the heart effects of this therapeutics, it is likely that it will prevent some COVID-19-associated arrhythmias, at least the ones promoted by hypoxia.

\section{Lymphopenia and Heart Function}

Endothelial cells are then incited on releasing even more chemokines and stimulating factors, in a positive feedback of proinflammatory response. ${ }^{30}$ This role of proinflammatory protein release, triggered by SARS$\mathrm{CoV}-2$, may be exacerbated, which would be classically called "the cytokine storm". ${ }^{51}$ This typical immunological pattern, found among patients with COVID-19, is currently correlated with the evolution of the disease to more severe stages. ${ }^{51}$ The "cytokine storm" is associated to the pathophysiology of the pneumonia and the Acute Respiratory Distress Syndrome (ARDS), on SARS-CoV-2 positive patients. ${ }^{51}$ In the heart, inflammation plays a critical role on CVDs, like acute coronary events, left ventricular remodeling and heart failure. ${ }^{52}$ Thus, the cytokine storm must raise attention to the cardiovascular consequences in COVID-19, since its cardiac deployments are already described. ${ }^{53}$ In this line, autopsies performed on COVID-19 deceased individuals have shown infiltration of interstitial mononuclear inflammatory cells on the myocardium, ${ }^{53}$ corroborating that the cytokine storm may lead to cardiac outcomes, in which myocarditis could be one of these possible consequences. ${ }^{3}$

Furthermore, lymphopenia was also documented on COVID-19 patients, specially associated to low levels of CD4+ and CD8+ T cells, despite the late high levels of antiviral factors interferons (IFN- $\gamma$ ), which are secreted, mainly, by CD4+ T cells. ${ }^{28}$ Lymphopenia is reversed by Tocilizumab, the anti-IL-6 antibody. ${ }^{54}$ This kind of immune pattern is usually correlated with the evolution of the disease and associated with more severe cases when compared to moderate ones. ${ }^{55}$ Studies already demonstrated that white blood cells count can be excellent predictor of coronary heart disease, as well as heart failure worst prognosis. ${ }^{52}$ One of the first works to demonstrate the association of lymphopenia and heart failure was the work of Hurdle, Gyde, \& Willoughby in 1966. ${ }^{56}$ The authors reported an association between the heart failure patients and the 'cold' controls in respect of lymphopenia, eosinopenia, and cortisol levels. ${ }^{56}$ In agreement with this data, a previous study have associate lymphopenia with worse outcomes in patients with heart failure, chronic ischemic heart disease and acute coronary syndromes. ${ }^{57}$ Also, the lymphopenia was proposed a key prognostic marker in heart failure. In this line it was demonstrated that lymphocyte count was inversely associated with survival at 1, 2 and 3 years after adjusting for clinical, laboratory, and pharmacological variables. ${ }^{58}$ As described above, within the cytokines, IL-1B plays an important role in the SARS-CoV-2 physiopathology. Other recent work also related the preoperative lymphopenia with worse survival in LVAD patients. ${ }^{59}$

Interferons, mainly type I/III, play a pivotal role when secreted early on viral infections, while its late secretion by the CD4+ T cells, which occurs on some COVID-19 patients, is correlated with poor prognosis. ${ }^{28}$ In addition, this unbalance between the CD4 cells and IFN concentration helps to explain, at least in part, the characteristic T cells exhaustion observed in these patients. ${ }^{28}$

As described above, both immune system and lung injury could be involving in the SARS-CoV-2-induced cardiac impairment. Since the cardiac cells also express ACE2 receptor, a direct infection could also justify tissue damage, by consequence of an increase apoptosis. In this direction, it was recently report evidences of a direct infection of cardiomyocytes by SARS-CoV-2. ${ }^{60}$ The most recent work of Lindner and coworkers (2020) documented the presence of SARS-CoV-2 in the heart of 24 of 39 patients (61.5\%). ${ }^{60}$ Additionally, the authors described viral load above 1000 copies per $\mu \mathrm{g}$ RNA in 16 of 39 patients $(41.0 \%)$. Interesting, there are studies that elucidates the possibility of viral infection on cardiac tissues, such as occurred by the influenza virus, resulting in myocarditis, which indicates that a direct infection should be directly involving in the cardiac physiopathology. ${ }^{61}$

\section{SARS-CoV-2 Infect Cardiomyocytes}

Several studies have shown presence of SARS-CoV-2 genome in the heart, as well as signs of viral myocarditis in COVID-19 infected individuals. ${ }^{6,60,62,63}$ Furthermore, the infection by the novel coronavirus also implicates in a large spectrum of symptoms, which may include arrhythmia and heart failure, as well as elevation of cardiac biomarkers. ${ }^{64}$ However, until now, the mechanisms involved in cardiac injury remains uncleared. Necropsy of myocardium from COVID-19 infected patients revealed, via PCR, that SARSCoV-2 viral RNA was detected in the heart. ${ }^{63}$ Indeed, it is notable that ACE2 receptor is expressed in cardiac tissue and that is upregulated during dilated and hypertrophic cardiomyopathy. ${ }^{65}$ Taken together, these findings give rise to the scientific community to hypothesize a direct infection of the novel coronavirus in cardiomyocytes (CM) 
as leading to possible cardiac disfunction. Elucidating the pathogenic mechanism of cardiac injury in COVID-19 in vitro could ultimately guide therapeutic strategies. ${ }^{66}$

In vitro research with human cardiomyocytes (CMs) is a challenge to science, once they are difficult to obtain and maintain throughout the course of tests. Improved methods to convert human induced pluripotent stem cells (hiPSCs) to multiple somatic lineages have enabled in vitro mass production of patient-specific cells, including hiPSC-derived CMs (hiPSC-CMs). ${ }^{67}$ The hiPSC-CMs can be differentiated by promoting the production and activation of an adult human CM-like protein pattern, in addition to be endowed with the capacity of spontaneous contraction. The whole process lasts few weeks, and it is made by using defined differentiation protocols, customized with genome editing. ${ }^{68}$ Currently, hiPSC-CMs are a well-established in vitro model to study the mechanisms of direct $\mathrm{CM}$ viral infection, especially in the context of viral myocarditis. ${ }^{66}$

The invasion of SARS-CoV-2 occurs by the interaction between the viral Spike glycoprotein and the target cells' ACE2 receptor. It is worth mentioning that the level of expression of ACE2 in hiPSC-CMs is comparable to those of VERO cells, ${ }^{69}$ a primate kidney epithelial line with established SARS-CoV-2 tropism. Normally, the Spikeprotein / ACE2 interaction is stabilized by the presence of TMPRSS2. However, both hiPSC-CM and adult human $\mathrm{CM}$ did not express this serine transmembrane protease. ${ }^{69}$ In contrast, single-cell RNA-sequencing analysis detected high levels of endosomal cysteine proteases CTSB and CTSL, generally co-expressed with ACE. ${ }^{66}$ This viral processing factors are important since they may cleave the glycoprotein spike and lead to endomembrane fusion-mediated release of SARS-CoV-2 genome inside the cytoplasm. ${ }^{69,70,71}$ Interestingly though, some scientists reported decreased viral detection of SARS-CoV-2 in CTSL inhibition, whereas blocking CTSB did not attenuate viral levels. In this regard, SARS-CoV-2 would bind to hiPSC-CMs via the ACE2 receptor and utilize a CTSL (but not CTSB)-dependent endolysosomal route to infection, independent of TMPRSS2/serine proteasemediated activation at the cellular membrane. ${ }^{72}$

In a recent study, Pérez-Bermejo et al. ${ }^{73}$ used analysis of single-cell RNA-sequencing and immunofluorescence staining of infected $\mathrm{CM}$ to revealed double-stranded RNA (indicative of replicating virus) and the viral spike protein initially placed near the nucleus, in endoplasmic reticulum-golgi intermediate compartment, suggesting a potential replication center. At $48 \mathrm{~h}$ after the infection, they visualized the dsRNA signal already dispersed throughout the cytoplasm. And, by $72 \mathrm{~h}$ post infection, SARS-CoV-2 was spread throughout the culture and a large portion of the CMs had died, with the remaining cells displaying dissociation from neighboring cells, heavily reduced sarcomeric staining and SARS-CoV-2 virions in large vesicles near to the nucleus.

Aiming to evaluate the electrophysiological properties of infected hiPSC-CM, Marchiano et al., ${ }^{66}$ culture these cells with SARS-CoV-2 by the multiplicity of infection (i.e., the number of infectious viral particles per cell) rate of 0.1 and 5. After 72 hours of observation, the analysis revealed, in different proportions, reduced beating rate, lower depolarization spike amplitude and decreased electrical conduction velocity of the cells. Indeed, in a specific model of stem cells-derived cardiomyocytes, the hESC-CMs, an increase in the duration of the field potential (FPD) was noticed. This fact may pave the way for further studies, once FPD may be interpreted as an in vitro surrogate of the QT interval measured by an electrocardiogram. ${ }^{66}$ Once QT prolongation is well-established as pro-arrhythmogenic, the authors suggests that the infection of the novel coronavirus in cardiomyocytes may lead to changes in electrophysiological properties that could even directly create a substrate for arrhythmias. Likewise, contractile properties of hiPSC-CMs were evaluated and a decrease of the maximal twitch force was detected after 72 hours of infection, and even after 144 hours. Taken together, these facts may contribute to whole-organ cardiac dysfunction seen in COVID-19 patients.

Transcriptomic analysis via RNA sequencing of infected hiPSC-CMs were performed to identify gene expression changes mediated by SARS-CoV-2. Sharma et al. ${ }^{67}$ described a correlation between the raise of cleaved caspase-3 levels and dsRNA positive cells, indicating a possible virus-induced apoptosis process. Furthermore, the analysis revealed that some immunomodulators, such as interleukins, were significantly upregulated in infected samples, along with antiviral response pathways genes such as OAS3. In contrast, the author described that the expression of CM markers TNNT2 and TNNC1 were significantly reduced in infected samples, along with mitochondrial genes related to oxidative phosphorylation, such as CKMT2, encoding for creatine kinase. In addition, consistent with prior reports in myocardium, ${ }^{73}$ ACE2 was significantly downregulated in SARS-CoV-2-infected hiPSC-CMs. To summarize, it is possible conclude that the infection of SARS-CoV-2 in hiPSC-CMs drove to a downregulation of transcriptional pathways related to mitochondrial function, oxidative phosphorylation, and cardiac function, whereas 
upregulated pathways included responses to organic substance, immune system processes, such as production of type I and type III interferons, ${ }^{66}$ and apoptosis.

Taken together, the data obtained in a SARS-CoV-2 direct infection upon hiPSC-CM experiments strongly suggest a direct deleterious effect of the virus upon cardiac cells are possible.

\section{Conclusions}

In summary the data collected here allow us to propose that the cardiac impairment by SARS-CoV-2 could be due: i. cytokines storm that a) directly impair the heart function or b) indirectly affects other organs, like lung, that impact the cardiac function; ii. secondarily to hypoxemia and respiratory failure; iii. as a consequence of lymphopenia; iv. Since the SARS-CoV-2 was detected in cardiac tissue and it infect hiPSC-CM a direct effect might be a new clinical entity as a "cardiac viruses" related to SARS-CoV-2. (See Figure 1)

\section{Potential Conflict of Interest}

No potential conflict of interest relevant to this article was reported.

\section{Sources of Funding}

This study was funded by Fundação Carlos Chagas Filho de Amparo à Pesquisa do Estado do Rio de Janeiro E-26/210.155/2020, E-26/203.169/2017, E-26/210.191/2020, and E-26/210.253/2020; CNPq: 310681/2018-9), CAPES, FINEP.

\section{Study Association}

This study is not associated with any thesis or dissertation work.

\section{Aprovação Ética e consentimento informado}

Este artigo não contém estudos com humanos ou animais realizados por nenhum dos autores.

\section{Author contributions}

Conception and design of the research: Vigário LC, Muradas G, Neto Paiva C, Medei E. Writing of the manuscript: Vigário LC, Muradas G, Neto Paiva C, Medei E. Critical revision of the manuscript for intellectual content: Vigário LC, Neto Paiva C, Medei E.

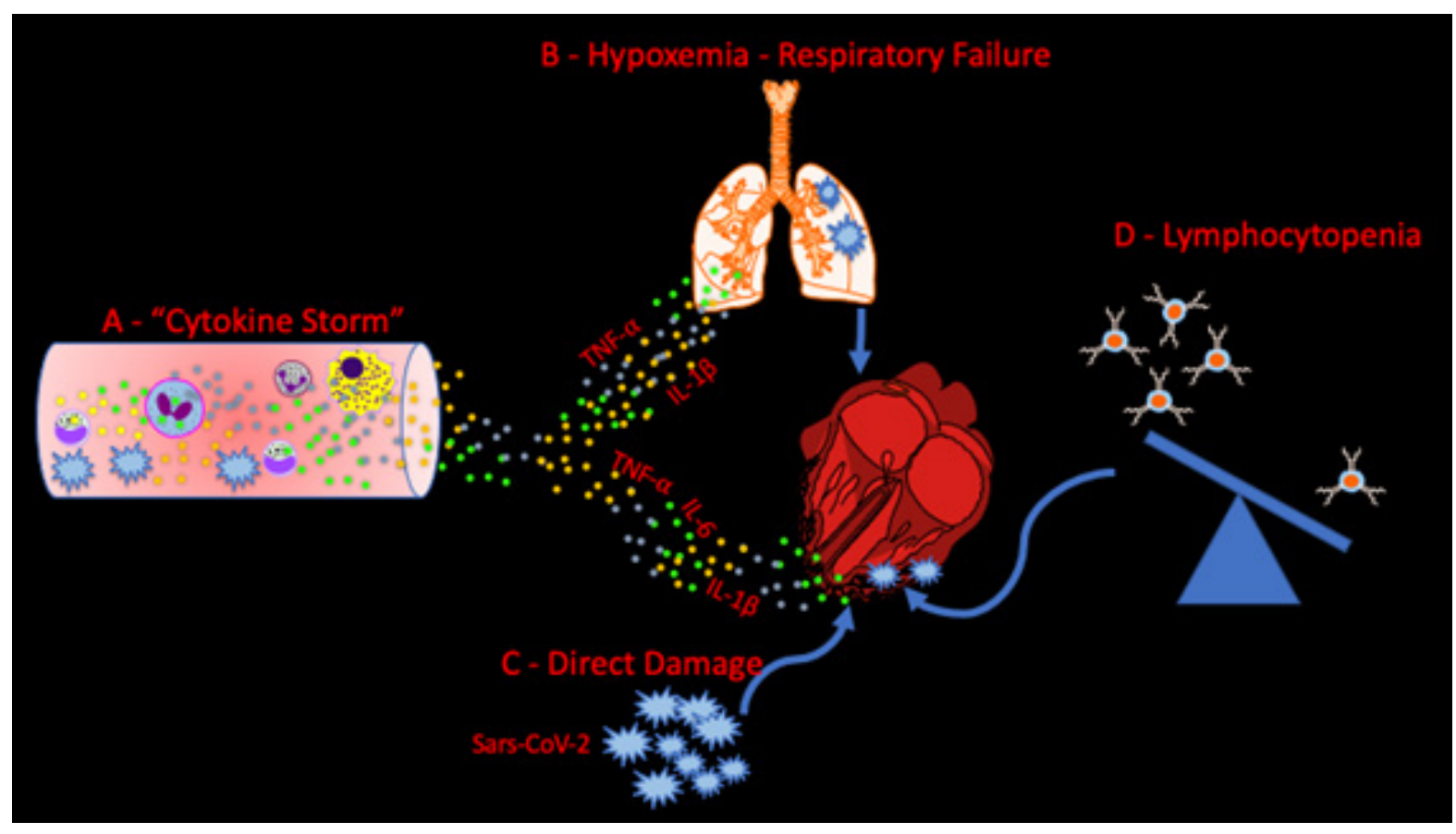

Figure 1 - The cartoon depicts the potential mechanisms involved on cardiac damage mediated by SARS-CoV-2. A - Represent the cytokine storm and the main cytokines involved; B - Cardiac impairment as a consequence of respiratory or respiratory disease; C- Direct SARS-CoV-2 infection upon cardiac tissue; D - The lymphopenia was pointed out as important marker and involving in heart disfunction. 


\section{References}

1. World Health Organization. (WHO). Geneva; 2018.

2. Guo T, Fan Y, Chen M, Wu X, Zhang L, He T, et al. Cardiovascular implications of fatal outcomes of patients with coronavirus disease 2019 (COVID-19). JAMA Cardiol. 2020; 5(7):1-8. doi: 10.1001/ jamacardio.2020.1017.

3. Rente A, Liezato D Jr, Uezato KMK. Coronavirus and the heart: a case report on the evolution of COVID-19 associated with cardiological evolution. Arq Bras Cardiol. 2020 .114(5):839-42. doi:10.36660/abc.20200263.

4. Grasselli G, Zangrillo A, Zanella A, Antonelli M, Cabrini L, Castelli A, et al. Baseline characteristics and outcomes of 1591 patients infected with SARS-CoV-2 admitted to ICUs of the Lombardy region, Italy. JAMA. 2020 Apr 6; 323(16):1574-81. doi: 10.1001/jama.2020.5394.

5. Brasil. Ministério da Saúde. Plataforma da saúde: dados abertos.[Citado em 202023 maio] Disponível em: Coronavirushttp://plataforma.saude. gov.br/coronavirus/dados-abertos/

6. Puntmann VO, Carerj ML, Wieters I, Fahim M, Arendt C, Hoffmann J, et al. Outcomes of cardiovascular magnetic resonance imaging in patients recently recovered from coronavirus disease 2019 (COVID-19). JAMA Cardiol. 2020;5(11):1265-73. doi:10.1001/jamacardio.2020.3557.

7. Januzzi Jr J. Troponin and BNP use in COVID-19. Cardiol Magazine. [Internet].[Citado em 201820 março]. Disponível em:accorg/latest-incardiology//articles/2020/03/18/troponin-and-bnp-use-in-covid19

8. Chapman AR, Bularga A, Mills NL. High-sensitivity cardiac troponin can be an ally in the fight against COVID-19. Circulation. 2020; 141(22):1733-5. doi: 10.1161/CIRCULATIONAHA.120.047008.

9. Sandoval Y, Januzzi Jr JL, Jaffe AS. Cardiac Troponin for the diagnosis and risk-stratification of myocardial injury in COVID-19: JACC review topic of the week. J Am Coll Cardiol. 2020 Jul 3; S0735-1097(20)35888-5. doi: 10.1016/j.jacc.2020.06.068.

10. Aikawa T, Takagi H, Ishikawa K, Kuno T. Myocardial injury characterized by elevated cardiac troponin and in-hospital mortality of COVID-19: an insight from a meta-analysis. J Med Virol. 2021;93(1):51-5. doi: 10.1002/jmv.26108.

11. Borghi MO, Beltagy A, Garrafa E, Curreli D, Cecchini G, Bodio C, et al. Anti-phospholipid antibodies in COVID-19 patients: are the antibodies really guilty?. MedRxiv. 2020 Jun 19; 2020.06.17.20134114 doi: 10.1101/2020.06.17.20134114.

12. Willyard C. Coronavirus blood-clot mystery intensifies. Nature. 2020 May; 581(7808):250. doi: 10.1038/d41586-020-01403-8.

13. Teuwen LA, Geldhof V, Pasut A, Carmeliet P. COVID-19: the vasculature unleashed. Nat Rev Immunol. 2020 Jul; 20(7):389-91. doi: 10.1038/s41577020-0343-0.

14. Zhang D, Zhou X, Yan S, Tian R, Su L, Ding X, et al. Correlation between cytokines and coagulation-related parameters in patients with coronavirus disease 2019 admitted to ICU. Clin Chim Acta. 2020 Jul 6; 510:47-53. doi: 10.1016/j.cca.2020.07.002.

15. Belani P, Schefflein J, Kihira S, Rigney B, Delman BN, Mahmoudi K, et al. COVID-19 is an independent risk factor for acute ischemic stroke. AJNR Am J Neuroradiol. 2020; 41(8):1361-4. doi: 10.3174/ajnr.A6650.

16. Patil NR, Herc ES, Girgis M. Cold agglutinin disease and autoimmune hemolytic anemia with pulmonary embolism as a presentation of COVID-19 infection. Hematol Oncol Stem Cell Therapy. 2020; s16583876(20):30116-3. doi: 10.1016/j.hemonc.2020.06.005.

17. McFadyen JD, Stevens H, Peter K. The emerging threat of (micro) thrombosis in COVID-19 and its therapeutic implications. Circ Res. 2020;127(4):571-87. doi: 10.1161/CIRCRESAHA.120.317447.

18. Pishgahi M, Aval ZA, Hajimoradi B, Bozorgmehr R, Safari S, Yousefifard M. Massive pulmonary thromboembolism in patients with COVID-19; report of three cases. Arch Acad Emerg Med. 2020 May 16; 8(1):e58. eCollection 2020.
19. Bavaro DF, Poliseno M, Scardapane A, Belati A, Gennaro ND, Ianora AAS, et al. Occurrence of acute pulmonary embolism in COVID-19-a case series. Int J Infect Dis. 2020; 98:225-6. doi: 10.1016/j.ijid.2020.06.066.

20. Yao X, Ye F, Zhang M, Cui C, Huang B, Niu P, et al. In vitro antiviral activity and projection of optimized dosing design of hydroxychloroquine for the treatment of severe acute respiratory syndrome coronavirus 2 (SARSCoV-2). Clin Infect Dis. 2020 Jul 28; 71(15): 732-9. doi: 10.1093/cid/ciaa237.

21. Gautret P, Lagier JC, Parola P, Hoang VT, Meddeb L, Mailhe M, et al. Hydroxychloroquine and azithromycin as a treatment of COVID-19: results of an open-label non-randomized clinical trial. Int J Antimicrob Agents. 2020 Jul; 56(1):105949. doi: 10.1016/j.ijantimicag.2020.105949.

22. Chorin E, Dai M, Shulman E, Wadhwani L, Bar-Cohen R, Barbhaiya C, et al. The QT interval in patients with COVID-19 treated with hydroxychloroquine and azithromycin. Nature Med. 2020 Jun; 26(6):8089. doi: 10.1038/s41591-020-0888-2.

23. Saleh M, Gabriels J, Chang D, Kim BS, Mansoor A, Mahmood E, et al. Effect of chloroquine, hydroxychloroquine, and azithromycin on the corrected QT interval in patients with SARS-CoV-2 infection. Circ Arrhythm Electrophysiol. 2020 Jun; 13(6):e008662. doi: 10.1161/ CIRCEP.120.008662.

24. Kochav SM, Coromilas E, Nalbandian A, Ranard LS, Gupta A, Chung MK, et al. Cardiac Arrhythmias in COVID-19 Infection. Circ Arrhythm Electrophysiol. 2020 Jun; 13(6):e008719. doi: 10.1161/CIRCEP.120.008719.

25. Bhatla A, Mayer MM, Adusumalli S, Hyman MC, Oh E, Tierney A, et al. COVID-19 and cardiac arrhythmias. Heart Rhythm. 2020 Jun 22; S15475271(20)30594-4. doi: 10.1016/j.hrthm.2020.06.016.

26. Yu CM, Wong RSM, Wu EB, Kong SL, Wong J, Yip GWK, et al. Cardiovascular complications of severe acute respiratory syndrome. Postgrad Med J. 2006 Feb; 82(964):140-4. doi: 10.1136/pgmj.2005.037515.

27. Pan SF, Zhang HY, Li CS, Wang C. Cardiac arrest in severe acute respiratory syndrome: analysis of 15 cases. Zhonghua Jie $\mathrm{He} \mathrm{He} \mathrm{Hu} \mathrm{Xi}$ Za Zhi. 2003 Oct; 26(10):602-5. PMID:14633442

28. Vabret N, Britton GJ, Gruber C, Hegde S, Kim J, Kuksin M, et al. Immunology of COVID-19: current state of the science. Immunity. 2020 Jun 16; 52(6):910-41. doi: 10.1016/j.immuni.2020.05.002.

29. Pedersen SF, Ho YC. SARS-CoV-2: a storm is raging. J Clin Invest. 2020 May 1; 130(5):2202-5. doi: 10.1172/JCI137647.

30. Li H, Liu L, Zhang D, Xu J, Dai H, Tang N, et al. SARS-CoV-2 and viral sepsis: observations and hypotheses. Lancet. 2020 May 9; 395(10235):151720. doi: 10.1016/S0140-6736(20)30920-X.

31. Herold T, Jurinovic V, Arnreich C, Lipworth BJ, Hellmuth JC, BergweltBaildon MV, et al. Elevated levels of IL- 6 and CRP predict the need for mechanical ventilation in COVID-19. J Allergy Clin Immunol. 2020 Jul; 146(1):128-136.e4. doi: 10.1016/j.jaci.2020.05.008.

32. Peiris JSM, Chu CM, Cheng VCC, Chan KS, Hung IFN, Poon LLM, et al. Clinical progression and viral load in a community outbreak of coronavirus-associated SARS pneumonia: a prospective study. Lancet. 2003 May 24; 361(9371):1767-72. doi: 10.1016/s0140-6736(03)13412-5.

33. Knorr JP, Colomy V, Mauriello CM, Ha S. Tocilizumab in patients with severe COVID-19: A single-center observational analysis. J Med Virol. 2020 Jun 17; 10.1002/jmv.26191. doi: 10.1002/jmv.26191.

34. Covid-19 severe baisse du risqué de deces avec le Tocilizumab dans létude britanique recovery. [Internet] [Cited in 2021 feb 21] Available from: https://www.apmnews.com/depeche/0/350489/premiere-etuderandomisee-favorable-au-tocilizumab-dans-le-covid-19\%2C-en-france

35. Luo M, Liu J, Jiang W, Yue S, Liu H, We S. IL-6 and CD8+ T cell counts combined are an early predictor of in-hospital mortality of patients with COVID-19. JCI Insight. 2020 Jul 9;5(13):139024. doi: 10.1172/jci. insight.139024. 
36. Anft M, Paniskaki K, Blazquez-Navarro A, Doevelaar AAN Seibert F, Hoelzer B, et al. COVID-19 progression is potentially driven by $\mathrm{T}$ cell immunopathogenesis. MedRxiv. 2020 May 19. doi: 10.1101/2020.04.28.20083089.

37. Aromolaran AS, Srivastava U, Alí A, Chahine M, Lazaro D, El-Sherif $\mathrm{N}$, et al. Interleukin-6 inhibition of hERG underlies risk for acquired long QT in cardiac and systemic inflammation. PLoS One. 2018 Dec 6; 13(12):e0208321. doi: 10.1371/journal.pone.0208321.

38. Kobayashi H, Kobayashi Y, Yokoe I, Kitamura N, Nishiwaki A, Takei M, et al. Heart rate-corrected QT interval duration in rheumatoid arthritis and its reduction with treatment with the interleukin 6 inhibitor tocilizumab. J Rheumatol. 2018 Dec; 45(12):1620-7. doi: 10.3899/jrheum.180065.

39. Lazzerini PE, Capecchi PL, Bertolozzi I, Morozzi G, Lorenzini S, Simpatico A, et al. Marked QTc prolongation and torsades de pointes in patients with chronic inflammatory arthritis. Front Cardiovasc Med. 2016 Sep 21; 3:31. doi: 10.3389/fcvm.2016.00031.

40. Janssen SP, Gayan-Ramirez G, Van den Bergh A, Herijgers P, Maes K, Verbeken E, et al. Interleukin-6 causes myocardial failure and skeletal muscle atrophy in rats. Circulation. 2005 Mar 1; 111(8):996-1005. doi: 10.1161/01.CIR.0000156469.96135.0D.

41. Finkel MS, Oddis CV, Jacob TD, Watkins SC, Hattler BG, Simmons RL. Negative inotropic effects of cytokines on the heart mediated by nitric oxide. Science. 1992 Jul 17; 257(5068):387-9. doi: 10.1126/science.1631560.

42. Villegas S, Villarreal FJ, Dillmann WH. Leukemia inhibitory factor and interleukin-6 downregulate sarcoplasmic reticulum Ca2+ATPase (SERCA2) in cardiac myo-cytes. Basic Res Cardiol. 2000 Feb; 95(1):47-54. doi: $10.1007 / \mathrm{s} 003950050007$

43. Ruan Q, Yang K, Wang W, Jiang L, Song J. Clinical predictors of mortality due to COVID-19 based on an analysis of data of 150 patients from Wuhan, China. Intensive Care Med. 2020 May; 46(5):846-8. doi: 10.1007/ s00134-020-05991-x

44. Schett G, Manger B, Simon D, Caporali R. COVID-19 revisiting inflammatory pathways of arthritis. Nat Rev Rheumatol. 2020 Aug; 16(8):465-70. doi: 10.1038/s41584-020-0451-z.

45. Szekely Y, Arbel Y. A review of interleukin-1 in heart disease: where Do we stand today?. Cardiol Ther. 2018 Jun; 7(1):25-44. doi: 10.1007/s40119018-0104-3.

46. Buckley LF, Abbate A. Interleukin-1 blockade in cardiovascular diseases: a clinical update. Eur Heart J. 2018 Jun 7; 39(22):2063-9. doi: 10.1093/ eurheartj/ehy128.

47. Monnerat G, Alarcón ML, Vasconcellos LR, Hochman-Mendez C, Brasil G, Bassani RA, et al. Macrophage-dependent IL-1 $\beta$ production induces cardiac arrhythmias in diabetic mice. Nat Commun. 2016 Nov 24; 7:13344 doi: 10.1038/ncomms13344.

48. Alarcon MML, Trentin-Sonoda M, Panico K, Schleier Y, Duque T, MorenoLoaiza O, et al. Cardiac arrhythmias after renal I/R depend on IL-1 $\beta$. J Mol Cell Cardiol. 2019 Jun; 131:101-11. doi: 10.1016/j.yjmcc.2019.04.025.

49. Cavalli G, Luca GD, Campochiaro C, Della-Torre E, Ripa M, Canetti D, et al. Interleukin-1 blockade with high-dose anakinra in patients with COVID-19, acute respiratory distress syndrome, and hyperinflammation: a retrospective cohort study. Lancet Rheumatol. 2020 Jun; 2(6):e325-e331. [Published online 2020 May 7]. doi: 10.1016/S2665-9913(20)30127-2.

50. Navarro-Millán I, Sattui SE, Lakhanpal A, Zisa D, Siegel CH, Crow MK. Use of anakinra to prevent mechanical ventilation in severe COVID-19: a case series. Arthritis Rheumatol. 2020 Jun 30; 10.1002/art.41422. doi: 10.1002/art.41422

51. Ye Q, Wang B, Mao J. The pathogenesis and treatment of the 'Cytokine Storm' in COVID-19. J Infec. 2020 Jun; 80(6): 607-13. doi: 10.1016/j. jinf.2020.03.037

52. Núñez J, Miñana G, Bodí V, Núñez E, Sanchis J, Husser O, et al. Low lymphocyte count and cardiovascular diseases. Curr Med Chem. 2011; 18(21):3226-33. doi: 10.2174/092986711796391633.
53. Chen C, Li H, Hang W, Wang DW. Cardiac injuries in coronavirus disease 2019 (COVID-19). J Mol Cell Cardiol. 2020 Jun 8;145:25-29. doi: 10.1016/j. yjmcc.2020.06.002.

54. Giamarellos-Bourboulis EJ, Netea MG, Rovina N, Akinosoglou K, Antoniadou A, Antonakos N, et al. Complex immune dysregulation in COVID-19 patients with severe respiratory failure. Cell Host Microbe. 2020 Jun 10; 27(6):992-1000.e3. doi: 10.1016/j. chom.2020.04.009.

55. Chen G, Wu D, Guo W, Cao Y, Huang D, Wang H, et al. Clinical and immunological features of severe and moderate coronavirus disease 2019. J Clin Invest. 2020 May 1; 130(5):2620-2629. doi: 10.1172/JCI137244.

56. Hurdle AD, Gyde OH, Willoughby JM. Occurrence of lymphopenia in heart failure. J Clin Pathol. 1966; 19(1):60-4. doi: 10.1136/jcp.19.1.60.

57. Agnoletti L, Curello S, Malacarne F, Airò P, Cargnoni A, Valgimigli $\mathrm{M}$, et al. Immune activation in severe heart failure: does etiology play a role?. Eur Heart J Supl.; 6 (Suppl. F), F22-9. doi: 10.1016/j. ehjsup.2004.09.014.

58. Levy WC, Mozaffarian D, Linker DT, Sutradhar SC, Anker SD, Cropp $A B$, et al. The Seattle heart failure model: prediction of survival in heart failure. Circulation. 2006; 113(11):1424-33. doi: 10.1161/ CIRCULATIONAHA.105.584102.

59. Stawiarski K, Agboola O, Park J, Geirsson A, Jacoby D, Bellumkonda L,et al. Impact of preoperative lymphopenia on survival following left ventricular assist device placement. ASAIO J. 2021 Jun 1;67(6):650-7. doi: 10.1097/MAT.0000000000001289.

60. Lindner D, Fitzek A, Bräuninger H, Alecheva G, Edler C, Meissner K, et al. Association of Cardiac Infection With SARS-CoV-2 in Confirmed COVID-19 Autopsy Cases. JAMA Cardiol. 2020;5(11):1281-5. doi:10.1001/ jamacardio.2020.3551

61. Huyut MA. Novel coronavirus pneumonia and cardiomyopathy: a case report. Arq Bras Cardiol. 2020 Jun 1; 114(5):843-5. doi: 10.36660/ abc. 20200268 .

62. Bradley B T, Maioli H, Johnston R, Chaudhry I, Fink SL, Xu H, et al. Histopathology and ultrastructural findings of fatal COVID-19 infections in Washington State: a case series. Lancet.2020;396(10247):320-32. doi:10.1016/S0140-6736(20)31305-2

63. Dolhnikoff M, Ferranti JF, Monteiro RAA, Duarte Neto AN, Soares GG,et al. SARS-CoV-2 in cardiac tissue of a child with COVID-19related multisystem inflammatory syndrome. Lancet Child Adolesc Health.2020;4(10):790-4. doi: doi.org:10.1016/S2352-4642(20)30257-1

64. Versteeg GA, Bredenbeek PJ, Worm SH, Spaan WJ. The coronavirus spike protein induces endoplasmic reticulum stress and upregulation of intracellular chemokine mRNA concentrations. J Virol.2007;361(1):18-26. doi:10.1016/j.virol.2007.01.020.

65. Puelles VG, Lutgehetmann M, Lindenmeyer MT, Sperhake JP, Wong MN, Allweiss L, et al. Multiorgan and Renal Tropism of SARSCoV-2. N Engl J Med.383(6):590-2. doi: https://doi.org/10.1056/ NEJMc2011400.

66. Tucker NR, Chaffin M, Bedi KC, Papaneli I, Akkad AD, Arduini A, et al. Myocyte Specific Upregulation of ACE2 in Cardiovascular Disease: Implications for SARS-CoV-2 mediated myocarditis. MedRxiv.2020. doi:2020.04.09.20059204.

67. Sharma A, Garcia G Jr, Wang Y,Plummer J, Morizono K, Arumugaswani W, et al. Human iPSC-Derived Cardiomyocytes Are Susceptible to SARS-CoV-2 Infection. Cell Rep Med. 2020;1(4):100052. doi:10.1016/j. xcrm.2020.100052

68. Marchiano S, Hsiang TY, Khanna A, Higashi T, Whitmore L, Bargehr J, et al. ARS-CoV-2 Infects Human Pluripotent Stem Cell-Derived Cardiomyocytes, Impairing Electrical and Mechanical Function. Stem Cell Rep; 2021;16(3):478-92. doi:10.1016/j.stemcr.2021.02.008

69. Sharma A, Toepfer CN, Ward T, Wasson L, Agarwal R,Conner DA, et al. CRISPR/Cas9-mediated fluorescent tagging of endogenous proteins 
in human pluripotent stem cells. Curr Prot Hum Genet. 2018;96:21.11.121.11.20. doi: $10.1002 /$ cphg.52.

70. Hoffmann M, Keine-Weber H, Schoeder S, Kruger N, Herrler T, Erichsen S, et al. SARS-CoV-2 Cell Entry Depends on ACE2 and TMPRSS2 and Is Blocked by a Clinically Proven Protease Inhibitor. Cell.2020;181(2):280. e8. doi: 10.1016/j.cell.2020.02.052

71. Cui J, Li F, Shi ZL. Origin and evolution of pathogenic coronaviruses. Nat Rev Microbiol.2019; 17(3): 181-92. doi:10.1038/s41579-018-0118-9
72. Kang YL, Chou YY, Rothlauf PW, Liu Z, Soh TK, Cureton D, et al. Inhibition of PIKfyve kinase prevents infection by Zaire ebolavirus and SARS-CoV-2. Proc Natl Acad Sci U S A. 2020;117(34):20803-13. doi:10.1073/pnas.2007837117

73. Pérez-BermejoJA, Kang S, Rockwood SJ, Simoneau CR, Joy DA, Ramadoss GN, et al. SARS-CoV-2 infection of human iPSC-derived cardiac cells predicts novel cytopathic features in hearts of COVID-19 patients. bioRxiv. 2020 Sep 12;2020.08.25.265561. doi:10.1101/2020.08.25.265561 